\title{
Randomized, multicenter study: on-demand versus continuous maintenance treatment with esomeprazole in patients with non- erosive gastroesophageal reflux disease
}

Ekkehard Bayerdörffer ${ }^{1 *}$, Marc-Andre Bigard ${ }^{2}$, Werner Weiss ${ }^{3}$, Fermín Mearin $^{4}$, Luis Rodrigo ${ }^{5}$, Juan Enrique Dominguez Muñoz ${ }^{6}$, Hennie Grundling ${ }^{7}$, Tore Persson ${ }^{8}$, Lars-Erik Svedberg ${ }^{8}$, Nanna Keeling ${ }^{8}$ and Stefan Eklund ${ }^{8}$

\begin{abstract}
Background: Most patients with gastroesophageal reflux disease experience symptomatic relapse after stopping acid-suppressive medication. The aim of this study was to compare willingness to continue treatment with esomeprazole on-demand versus continuous maintenance therapy for symptom control in patients with non-erosive reflux disease (NERD) after 6 months.

Methods: This multicenter, open-label, randomized, parallel-group study enrolled adults with NERD who were heartburn-free after 4 weeks' treatment with esomeprazole $20 \mathrm{mg}$ daily. Patients received esomeprazole $20 \mathrm{mg}$ daily continuously or on-demand for 6 months. The primary variable was discontinuation due to unsatisfactory treatment. On-demand treatment was considered non-inferior if the upper limit of the one-sided $95 \%$ confidence interval $(\mathrm{Cl})$ for the difference between treatments was $<10 \%$.

Results: Of 877 patients enrolled, 598 were randomized to maintenance treatment (continuous: $n=297$; on-demand: $n=301$ ). Discontinuation due to unsatisfactory treatment was $6.3 \%$ for on-demand and $9.8 \%$ for continuous treatment (difference $-3.5 \%$ [90 \% Cl: $-7.1 \%, 0.2 \%]$ ). In total, 82.1 and $86.2 \%$ of patients taking on-demand and continuous therapy, respectively, were satisfied with the treatment of heartburn and regurgitation symptoms, a secondary variable $(P=\mathrm{NS})$. Mean study drug consumption was 0.41 and 0.91 tablets/day, respectively. Overall, $5 \%$ of the on-demand group developed reflux esophagitis versus none in the continuous group $(P<0.0001)$. The Gastrointestinal Symptom Rating Scale Reflux dimension was also improved for continuous versus on-demand treatment. Esomeprazole was well tolerated.
\end{abstract}

Conclusions: In terms of willingness to continue treatment, on-demand treatment with esomeprazole 20 mg was non-inferior to continuous maintenance treatment and reduced medication usage in patients with NERD who had achieved symptom control with initial esomeprazole treatment.

Trial registration: ClinicalTrials.gov identifier (NCT number): NCT02670642; Date of registration: December 2015.

Keywords: Discontinuation, Esomeprazole, Gastroesophageal reflux disease, Heartburn, Non-erosive reflux disease, On-demand

\footnotetext{
* Correspondence: bayerdoerffer@gmx.de

Lars-Erik Svedberg and Nanna Keeling were AstraZeneca employees at the

time the study was conducted, but no longer work for AstraZeneca.

'Department of Internal Medicine, Lohr Health Centre, Lohr, Germany

Full list of author information is available at the end of the article
} 


\section{Background}

Gastroesophageal reflux disease (GERD) is a chronic condition characterized by a range of symptoms, the most important of which are heartburn and regurgitation [1, 2]. Population-based studies have shown that these symptoms affect as many as $20 \%$ of people on a weekly basis [3]. Although GERD is associated with reflux esophagitis, which can be detected and confirmed by esophageal endoscopy, as many as $70 \%$ of patients with GERD display no such endoscopic findings and are thus termed as having endoscopy-negative or nonerosive reflux disease (NERD) [4]. Despite the absence of esophagitis, many of these patients experience a significant impairment in their health-related quality of life (HRQoL), similar to that experienced by patients with reflux esophagitis [4-6].

As the severity of symptoms generally correlates with esophageal acid exposure [7, 8], the most effective treatment for GERD, including NERD, is acid-suppressive therapy with a proton pump inhibitor (PPI) [9]. It has been shown that continuous maintenance treatment with the PPI esomeprazole (20 mg once daily) provides more effective acid suppression and maintained intragastric $\mathrm{pH}>4$ for a greater period of time than maintenance omeprazole, lansoprazole, pantoprazole or rabeprazole in patients with GERD $[10,11]$. In addition, a study by Talley et al. showed that, in patients with NERD, 6 months' on-demand treatment with esomeprazole $20 \mathrm{mg}$ controlled symptoms in $92 \%$ of patients who were using only $33 \%$ of the medication needed for daily continuous treatment [12]. In our study, we compared the efficacy of on-demand versus continuous esomeprazole maintenance treatment in patients with NERD (who had complete resolution of heartburn symptoms following initial treatment with esomeprazole) in terms of the willingness of patients to continue therapy.

\section{Methods \\ Patients}

Patients presenting to their general practitioner or gastrointestinal (GI) specialist with symptoms suggestive of GERD and with heartburn as their predominant symptom for longer than 6 months were considered for study entry. In addition, patients were included if they met the following inclusion criteria: age $\geq 18$ years (Austria, $\geq 19$ years); heartburn occurring for $\geq 4$ days during the last 7 days before endoscopy; or, if PPI therapy had been started within the last 7 days before endoscopy, heartburn occurring for $\geq 4$ days during the last 7 days before the start of PPI treatment.

Patients were excluded if they had any of the following: significant GI disorders or other disorders likely to affect the outcome of the study; gastroduodenal ulcers within the previous 2 years; previous esophageal, gastric or duodenal surgery (except closure and oversewing of an ulcer); irritable bowel syndrome; PPI use for either $\geq 10$ of the 28 days before endoscopy or $\geq 5$ of the 7 days before endoscopy; use of concomitant therapy likely to affect the outcome of the trial; pregnancy or lactation; childbearing potential unless taking effective contraception; and alcohol or drug abuse.

\section{Study design}

This was a multicenter, open-label, randomized, parallelgroup study (Fig. 1). Patients were enrolled at 61 centers in Austria, France, Germany, South Africa and Spain

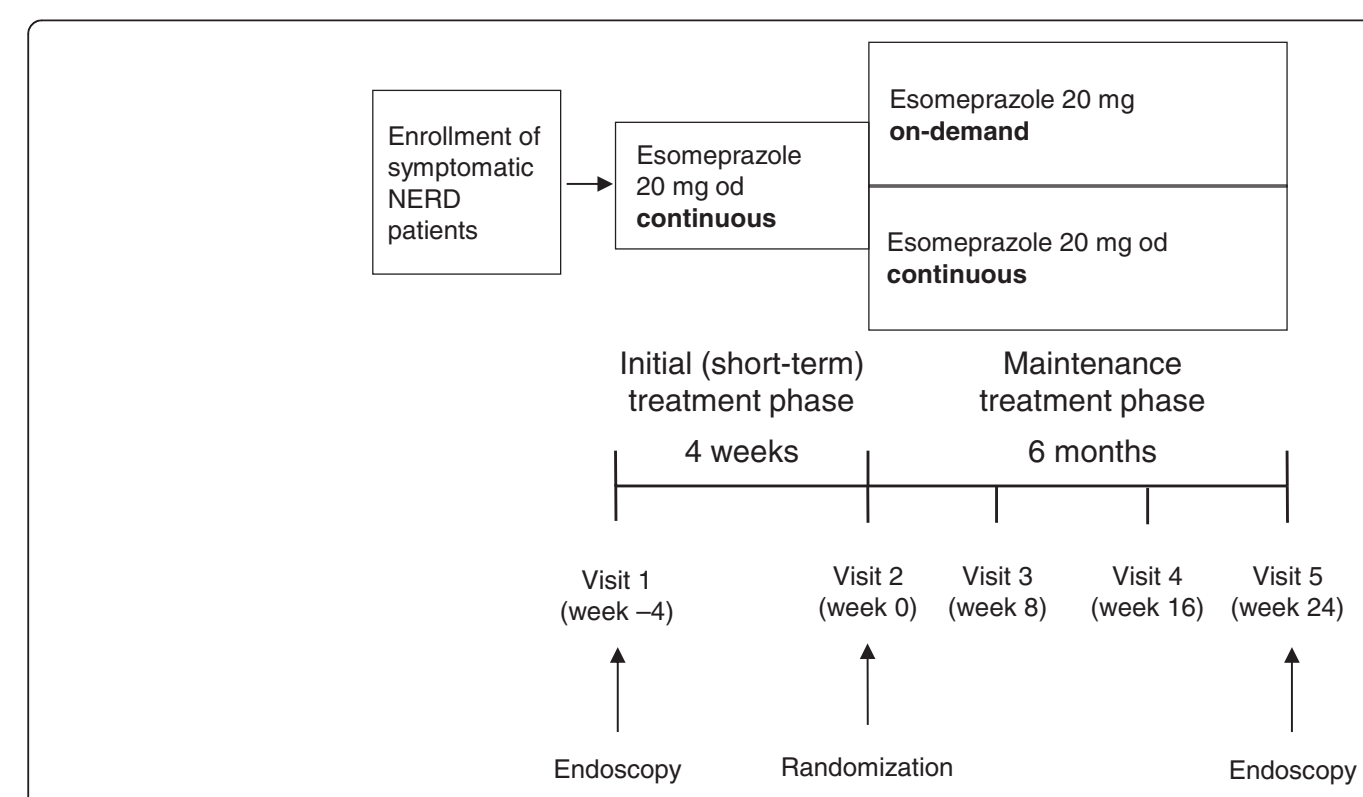

Fig. 1 Study design. Abbreviations: NERD, non-erosive reflux disease (without mucosal breaks on pre-treatment endoscopy); od, once daily 
between August 2001 and April 2002. The study was performed in accordance with the most recent amendment to the Declaration of Helsinki and complied with Good Clinical Practice. At each participating center, a local independent ethics committee or institutional review board approved the final study protocol. Signed informed consent was obtained from all patients before conducting any specific procedures for the study.

At visit 1 (week -4 ), a medical history was taken, and physical examination and endoscopy were performed. Endoscopy was performed again at visit 2 (week 0), and patients with reflux esophagitis detected at either visit 1 or 2 were excluded from randomization. Reflux esophagitis was defined as endoscopy-confirmed mucosal breaks [13]. Helicobacter pylori status was assessed at visit 1 on two antral and two corpus biopsy specimens. Specimens were evaluated by one central pathologist according to the criteria of the Sydney classification [14]. Patients with positive $H$. pylori status did not receive any eradication treatment during the study period.

All eligible patients underwent an initial (short-term) treatment period of 4 weeks with esomeprazole $20 \mathrm{mg}$ tablets once daily (administered as $22.3 \mathrm{mg}$ esomeprazole magnesium trihydrate). Severity of symptoms (heartburn, acid regurgitation, dysphagia and epigastric pain) was assessed as none, mild, moderate or severe at visits 1 (week -4) and 2 (week 0) using standard questions posed by the investigator. The frequency of heartburn was also reported. Only patients who were free from heartburn at visit 2 (defined as 7 symptom-free days in the last week of the short-term treatment phase; i.e., complete resolution of symptoms) were randomized sequentially (1:1) to one of two treatment groups for a 6month maintenance treatment phase. Patients in the on-demand treatment group received esomeprazole $20 \mathrm{mg}$ tablets (up to a maximum of once daily), taken as needed to adequately control their reflux symptoms; treatment could be taken to prevent symptoms, to soothe symptoms, or both. Specific circumstances prompting each on-demand use of esomeprazole were not recorded, although at the end of the 6-month treatment period patients were asked whether they had taken their medicine to soothe or prevent symptoms, or both. Patients in the continuous treatment group received esomeprazole $20 \mathrm{mg}$ tablets once daily continuously (Fig. 1). Randomization was performed using a computer program at AstraZeneca in balanced blocks using a blocking size of 2 .

Other PPIs and $\mathrm{H}_{2}$-receptor antagonists were not permitted during treatment. Antacids could only be taken between initial endoscopy and first administration of study drug.

\section{Study measurements and variables}

The primary variable was the proportion of patients discontinuing the study as a result of unsatisfactory treatment. At clinical visits 2 to 5 (weeks $0,8,16$ and 24 of the maintenance treatment phase) the investigator confirmed with the patient if he/she wished to continue with the treatment and, if not, the date and reasons for discontinuation were recorded. Following discontinuation of esomeprazole, patients were treated at the discretion of their investigator with medicines that were available in their country.

Secondary variables included the reasons given for treatment discontinuation, including: dissatisfaction with symptom control, the method of administration (on-demand or continuous) or taste/size of the pill; adverse events (AEs); protocol non-compliance; inclusion criteria not fulfilled (retrospective); patient lost to followup; improvement/recovery as evaluated by the investigator; or other reason specified by the investigator.

Treatment satisfaction was evaluated using a standardized questionnaire completed by patients at visits 2 to 5 (weeks $0,8,16$ and 24 of the maintenance treatment phase), or at premature discontinuation. The questionnaire comprised three questions: "How satisfied or dissatisfied are you with the effect of the drug?"; "How satisfied or dissatisfied are you with the way of taking the drug?"; and "Overall, how satisfied or dissatisfied are you with the way of treating your heartburn and regurgitation symptoms?". Patients were asked to give their answers as "completely satisfied", "quite satisfied", "neither satisfied nor dissatisfied", "quite dissatisfied" or "completely dissatisfied". For the purpose of this analysis, "satisfied" was defined as the sum of the upper two ratings ("completely satisfied" and "quite satisfied").

The intake of study medication was registered using the MEMS ${ }^{\circ}$ device, which utilizes a microelectronic recorder recessed in the cap of a drug container (Medical Event Monitoring System, Aardex, Zug, Switzerland). At each opening and closure of the container, the date and time of day was automatically recorded. This information was analyzed at the end of the study.

The evaluation of patient-reported outcomes focused on reflux symptoms and the impact on patients' quality of daily life. Symptom assessments were carried out using a standardized patient-reported outcomes questionnaire, the Gastrointestinal Symptom Rating Scale (GSRS), which has been validated in symptomatic GERD [15]. The GSRS consists of 15 GI symptoms grouped into 5 dimensions. Each dimension is scored on a 7 point scale, with a lower score indicating a lower perceived symptom severity. HRQoL assessments were made using the Quality of Life in Reflux and Dyspepsia (QOLRAD) instrument $[16,17]$, which was specifically developed for patients with symptoms of reflux and 
dyspepsia. The QOLRAD questionnaire consists of 25 items grouped into 5 dimensions representing different aspects of the daily life of patients with GERD. The questionnaire uses a similar 7-point scoring system to the GSRS; however, a lower score indicates a more severe impact on daily functioning. The GSRS and QOLRAD questionnaires were completed by the patients prior to treatment starting at visit 1 and at all subsequent visits. The changes in these parameters from start of the short-term and maintenance treatment phases to the end of the study were assessed and compared between the two treatments.

Data for all patient-reported outcomes were collected electronically by patients using a hand-held computer (Newton MessagePad 130/2000; Apple Computer, Inc., Cupertino, CA, USA). Use of an electronic questionnaire, rather than a paper-based format, was selected in view of the associated benefits of completeness of data, speed of data flow and ease of data handling [18].

\section{Safety and tolerability}

$\mathrm{AE}$ and serious $\mathrm{AE}$ (SAE) assessments were recorded throughout the short-term and maintenance treatment phases of the study (visits 1-5). Blood samples for laboratory screening were taken before administration of the study drug (at visit 1) and at study end point or premature discontinuation.

\section{Endoscopic assessment}

An endoscopic assessment of the esophageal mucosa was performed at visits 1 (or 7 days before) and 5 (end of study), and for all patients who left the study prematurely. The Los Angeles (LA) classification system [19] was used to grade the appearance of mucosal breaks.

\section{Statistical analysis}

The proportion of patients who were free of heartburn at the end of the initial 4-week treatment phase was calculated for the safety population, which comprised all patients who took at least one dose of study drug and for whom post-dose information was available. All patients randomized to maintenance treatment were included in the intention-to-treat (ITT) analysis set, and the primary variable was analyzed for these patients. ITT data were analyzed using the last-visit-carried-forward method for those patients who discontinued prematurely, and all patients who discontinued were regarded as having discontinued due to unsatisfactory treatment. ITT patients were included in the per-protocol (PP) analysis set if they were assessed for the primary variable. Patients were excluded from the PP population due to: violation of the inclusion/exclusion criteria; treatment with disallowed concomitant medication; compliance less than $75 \%$ in the treatment period; or other deviations from study procedures.

Estimates and two-sided $90 \%$ confidence intervals (CIs) were calculated for the difference between the ondemand and continuous treatment groups in the proportion of patients who discontinued prematurely because of dissatisfaction with study treatment. On-demand treatment was considered to be non-inferior to continuous treatment if the one-sided $95 \% \mathrm{CI}$ for the difference between treatments, shown by the upper bound of the two-sided $90 \% \mathrm{CI}$, was less than $10 \%$, as pre-specified in the clinical study protocol $[12,20]$. The difference between the groups in the proportion of patients who discontinued (overall and due to an AE) was compared using Chi-square tests with Yates' correction.

The secondary variables were analyzed for the ITT population only. The reasons for discontinuation from treatment and drug usage (date and time recorded by the $\mathrm{MEMS}^{\circ}$ device) were recorded descriptively.

Results from the treatment satisfaction questions were presented using estimates for the proportion of satisfied patients for the two treatment groups. In addition, estimates and two-sided $95 \%$ CIs (based on normal approximation) for the treatment difference in the proportion of satisfied patients were assessed.

For patient-reported changes in symptoms and HRQoL, the changes from baseline visit 1 (week -4 ) to end point and from visit 2 (week 0 ) to end point were calculated for the separate dimensions of GSRS and QOLRAD with two-sided $95 \%$ CIs. The differences between the two treatment groups were compared for each dimension using analysis of variance.

Safety data were presented for the safety population (as defined above).

\section{Determination of sample size}

Sample size was calculated from numbers needed to show that on-demand treatment was non-inferior to continuous treatment based on the proportion of patients who would discontinue the study prematurely because of unsatisfactory therapy. As outlined above, on-demand treatment was defined as non-inferior to continuous treatment if the upper bound of the two-sided $90 \% \mathrm{CI}$ for the difference in proportions (on-demand minus continuous) was less than $10 \%$.

With a sample size of 275 patients in each treatment group, a one-sided test of proportions at the $5 \%$ level had $90 \%$ power to reject the hypothesis that ondemand treatment is inferior to continuous treatment. With an estimated $10 \%$ non-evaluable patients and assuming that only $60 \%$ of the patients would be randomized (conservative estimates based on data from previous studies), it was calculated that 1020 patients 
would be required in the initial treatment phase to yield sufficient power.

\section{Results}

\section{Patient disposition and demographics}

Patients were enrolled at 6 centers in Austria $(n=65)$, 27 in France $(n=211), 14$ in Germany $(n=182), 9$ in South Africa $(n=289)$ and 5 in Spain $(n=130)$. Patient disposition through each stage of the study is shown in Fig. 2. In total, 877 patients were enrolled at visit 1 and 598 (68 \%) eligible patients were randomized to maintenance treatment at visit 2 . The safety population comprised 674 patients during the short-term treatment phase and 595 patients (on-demand, $n=301$; continuous, $n=294$ ) during the maintenance treatment phase. During the 4-week short-term treatment period, a high proportion of patients (619/674, $92 \%$ ) were free of heartburn (investigator-assessed); this was one of the eligibility criteria for the maintenance treatment phase of the study.

All 598 patients randomized to the maintenance treatment phase were included in the ITT analysis and 483 of these fulfilled the criteria for inclusion in the PP analysis. Of the 279 patients who were enrolled into the study but not randomized, 202 did not fulfil the eligibility criteria (most because of the presence of esophagitis at endoscopic examination at either the enrollment or randomization visit), including 44 patients who had heartburn for at least one day in the week prior to randomization. Of the 115 patients excluded from the PP analysis, 36 had received disallowed medication during maintenance treatment. Overall, the maintenance treatment groups were well balanced with respect to demographic and baseline characteristics (Table 1).

When viewed by country, the demographic data were similar in terms of age and gender. Austria, Germany and France showed similar proportions of patients who were H. pylori-positive (26.7, 28.8 and $34.2 \%$, respectively). However, the proportions for South Africa and Spain were noticeably higher (63.4 and $54.7 \%$, respectively).

\section{Primary variable}

In total, 48 (8.0\%) patients discontinued from the study prematurely, $19(6.3 \%)$ in the on-demand treatment

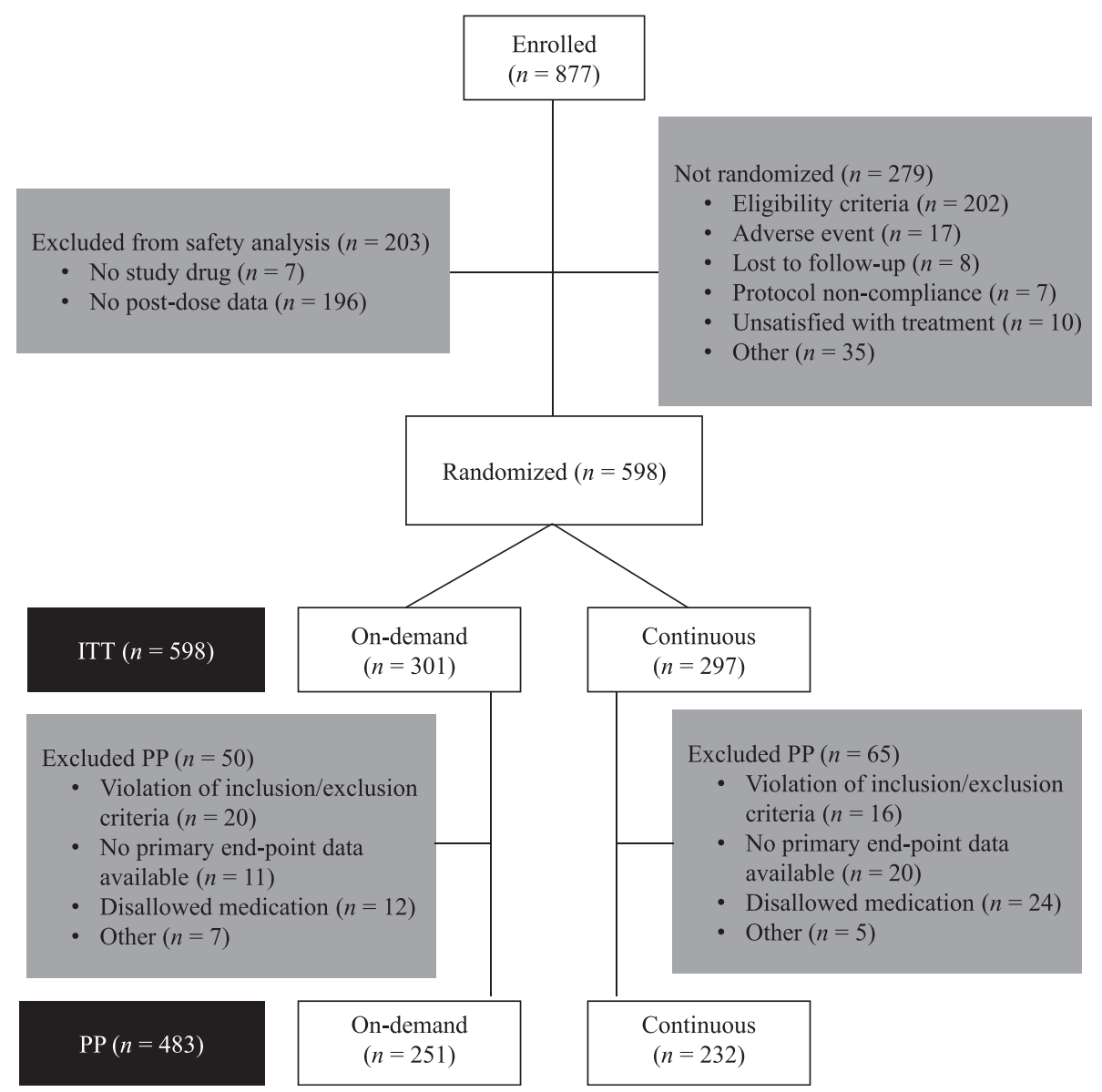

Fig. 2 Flow diagram of patients' disposition through the stages of the study. Abbreviations: ITT, intention-to-treat; PP, per-protocol 
Table 1 Baseline demographics (intention-to-treat population)

\begin{tabular}{|c|c|c|}
\hline Characteristic & $\begin{array}{l}\text { On-demand } \\
(n=301)\end{array}$ & $\begin{array}{l}\text { Continuous } \\
(n=297) \\
\end{array}$ \\
\hline Men, $n(\%)$ & $122(40.5)$ & $130(43.8)$ \\
\hline Women, $n(\%)$ & $179(59.5)$ & $167(56.2)$ \\
\hline \multicolumn{3}{|l|}{ Ethnicity, n (\%) } \\
\hline White & $259(86.0)$ & $255(85.9)$ \\
\hline Black & $14(4.7)$ & $10(3.4)$ \\
\hline Asian & $1(0.3)$ & $4(1.3)$ \\
\hline Other $^{a}$ & $27(9.0)$ & $28(9.4)$ \\
\hline Age $(y)$, mean $\pm S D$ & $48.2 \pm 13.6$ & $47.6 \pm 15.1$ \\
\hline Height $(\mathrm{cm})$, mean $\pm \mathrm{SD}$ & $167.0 \pm 9.1$ & $167.0 \pm 9.9$ \\
\hline Weight $(\mathrm{kg})$, mean \pm SD & $75.1 \pm 14.3$ & $75.8 \pm 14.7$ \\
\hline Hiatal hernia, $n(\%)$ & $96(31.9)$ & $108(36.4)$ \\
\hline \multicolumn{3}{|l|}{ Days with heartburn, n (\%) } \\
\hline $4 d$ & $26(8.6)$ & $31(10.4)$ \\
\hline $5 d$ & $55(18.3)$ & $46(15.5)$ \\
\hline $6 d$ & $46(15.3)$ & $42(14.1)$ \\
\hline $7 d$ & $174(57.8)$ & $178(59.9)$ \\
\hline \multicolumn{3}{|l|}{ Severity of heartburn, $n(\%)$} \\
\hline Mild & $21(7.0)$ & $19(6.4)$ \\
\hline Moderate & $165(54.8)$ & $153(51.5)$ \\
\hline Severe & $115(38.2)$ & $125(42.1)$ \\
\hline \multicolumn{3}{|l|}{ Severity of acid regurgitation, $n(\%)$} \\
\hline None & $82(27.2)$ & $63(21.2)$ \\
\hline Mild & $68(22.6)$ & $76(25.6)$ \\
\hline Moderate & $95(31.6)$ & $95(32.0)$ \\
\hline Severe & 56 (18.6) & $63(21.2)$ \\
\hline \multicolumn{3}{|l|}{ Severity of epigastric pain, $n$ (\%) } \\
\hline None & $133(44.2)$ & $129(43.4)$ \\
\hline Mild & $96(31.9)$ & $81(27.3)$ \\
\hline Moderate & $54(17.9)$ & $64(21.5)$ \\
\hline Severe & $18(6.0)$ & $23(7.7)$ \\
\hline \multicolumn{3}{|l|}{ Severity of dysphagia, $n(\%)$} \\
\hline None & $265(85.0)$ & $255(85.9)$ \\
\hline Mild & $28(9.3)$ & $22(7.4)$ \\
\hline Moderate & $14(4.7)$ & $14(4.7)$ \\
\hline Severe & $3(1.0)$ & $6(2.0)$ \\
\hline Helicobacter pylori-positive, $n$ (\%) & $125(41.5)$ & $130(43.8)$ \\
\hline
\end{tabular}

ancluding patients of mixed ethnicity

Abbreviation: $S D$ standard deviation

group and $29(9.8 \%)$ in the continuous treatment group $(P=0.15)$. In the ITT analysis, all premature discontinuations were regarded as being due to unsatisfactory treatment. The distribution of reasons for discontinuation was similar in the two treatment groups (Table 2). Five patients (on-demand, $n=3$; continuous, $n=2$ )
Table 2 Reasons for discontinuation due to unsatisfactory treatment (intention-to-treat population)

\begin{tabular}{lll}
\hline & \multicolumn{2}{l}{ Patients [n (\%)] } \\
\cline { 2 - 3 } & $\begin{array}{l}\text { On-demand } \\
(n=301)\end{array}$ & $\begin{array}{l}\text { Continuous } \\
(n=297)\end{array}$ \\
\hline Eligibility criteria not fulfilled & $4(1.3)$ & $6(2.0)$ \\
Adverse events & $1(0.3)$ & $6(2.0)$ \\
Improvement/recovery & 0 & $2(0.7)$ \\
Lost to follow-up & $6(2.0)$ & $7(2.4)$ \\
Protocol non-compliance & $2(0.7)$ & $2(0.7)$ \\
Unsatisfied with symptom control & $3(1.0)$ & $2(0.7)$ \\
Other & $3(1.0)$ & $4(1.3)$ \\
Total & $19(6.3)$ & $29(9.8)^{a}$ \\
\hline${ }^{a}$ Difference versus on-demand treatment was not significant $(P=0.15)$
\end{tabular}

actively reported that they discontinued the study because of unsatisfactory control of symptoms and no patient in either group discontinued because of dissatisfaction with the way of taking the drug or the taste/size of the tablet.

For the primary variable (discontinuation because of unsatisfactory treatment), on-demand treatment was non-inferior to continuous treatment, as shown by the upper confidence limit ( $90 \% \mathrm{CI}$ ) of the difference between on-demand and continuous treatment being less than $10 \%$ in both the ITT and PP analyses (Table 3).

The number of patients who discontinued prematurely from the study in each country was: Austria, 2 (3.3\%); France, 13 (8.5\%); Germany, 10 (6.8 \%); South Africa, 14 (8.5\%); and Spain, 9 (12.0\%). When the primary variable was assessed by $H$. pylori status, a similar number of patients discontinued prematurely from the study whether they were $H$. pylori-positive $(21$ [8.2\%]) or not $(27[7.9 \%])$.

\section{Secondary variables}

There was no statistically significant difference between the two treatment groups regarding the proportion of patients who responded that they were satisfied overall with the way their heartburn and regurgitation symptoms were being treated at 6 months $(82.1$ and $86.2 \%$ for on-demand and continuous treatment, respectively; difference $-4.1 \%$ [95 \% CI: $-10.0 \%, 1.7 \%]$ ]). Similarly, there was no statistically significant difference in the proportion of patients satisfied with the way they were taking the treatment $(81.7$ and $82.8 \%$ for on-demand and continuous treatment, respectively; difference $-1.1 \%$ [95 \% CI: $-7.2 \%, 5.0 \%]$ ]) and the effect of treatment (78.7 and $84.8 \%$, respectively; difference $-6.1 \%$ [95 \% CI: $-12.3 \%, 0.1 \%]$ ).

Among patients with evaluable data (on-demand, $n=$ 295; continuous, $n=286$ ), mean drug usage over the 6month study period was 0.41 (standard deviation [SD], 0.25 ) tablets (doses) per day in the on-demand treatment 
Table 3 Percentage of patients discontinuing due to unsatisfactory treatment in the intention-to-treat (ITT) and per-protocol (PP) populations

\begin{tabular}{lll}
\hline Treatment & $\begin{array}{l}\text { Percentage of } \\
\text { patients }(n)\end{array}$ & $\begin{array}{l}90 \% \text { confidence } \\
\text { interval }\end{array}$ \\
\hline $\begin{array}{l}\text { ITT population } \\
\text { Esomeprazole on-demand } \\
(n=301)\end{array}$ & $6.3(19)$ & \\
$\begin{array}{l}\text { Esomeprazole continuous } \\
(n=297)\end{array}$ & $9.8(29)$ & $-7.1,0.2$ \\
$\begin{array}{l}\text { Difference (on-demand minus } \\
\text { continuous) }\end{array}$ & -3.5 & \\
PP population & & \\
$\begin{array}{l}\text { Esomeprazole on-demand } \\
\text { ( } n=251)\end{array}$ & $1.2(3)$ & \\
$\begin{array}{l}\text { Esomeprazole continuous } \\
\text { ( } n=232)\end{array}$ & $0.4(1)$ & $-0.6,2.1$ \\
Difference (on-demand minus & 0.8 & \\
continuous) & & \\
\hline
\end{tabular}

group and 0.91 (SD, 0.16) tablets per day in the continuous treatment group. Most patients took their medication in the morning (on-demand, $54.2 \%$; continuous, $72.5 \%)$. In the on-demand treatment group, an analysis of reasons for taking the medication showed that more patients took their medication to soothe rather than to prevent symptoms (Table 4). However, most patients took medication to prevent symptoms at least once during the study.

The final endoscopy showed that most patients remained free of reflux esophagitis at the end of the 6month treatment period; 15 patients (5\%), all in the ondemand treatment group, had endoscopic evidence of mucosal breaks at the end of the study $(P<0.0001$ versus continuous treatment). Of these patients, 14 had LA grade A esophagitis and 1 had LA grade $B$.

From baseline to the end of the 4-week short-term treatment period (visit 1 to visit 2), large improvements in the GSRS Indigestion, Abdominal Pain and Reflux dimensions and in all QOLRAD dimensions were observed. During the randomized part of the study (maintenance therapy), further small improvements in

Table 4 Reasons for drug intake in the esomeprazole on-demand treatment arm (intention-to-treat population, $n=301$ )

\begin{tabular}{ll}
\hline $\begin{array}{l}\text { Have you taken your medicine to soothe } \\
\text { or prevent symptoms? }\end{array}$ & Patients $[n(\%)]$ \\
\hline To soothe & $85(28.2)$ \\
Mainly to soothe, sometimes to prevent & $66(21.9)$ \\
To both soothe and prevent & $59(19.6)$ \\
Mainly to prevent, sometimes to soothe & $28(9.3)$ \\
To prevent & $15(5.0)$ \\
Missing & $48(15.9)$ \\
\hline
\end{tabular}

scores were seen for the GSRS Indigestion and Abdominal pain dimensions in the continuous treatment group. Small improvements were also seen from baseline to the end of short-term treatment and to the end of maintenance treatment for the GSRS Diarrhea and Constipation dimensions. These improvements were evident in both the on-demand and continuous treatment groups. The mean GSRS scores at baseline, the end of short-term treatment and the end of maintenance treatment are shown in Fig. 3a. The estimated differences in the change in GSRS scores from baseline to the end of maintenance treatment between the continuous and on-demand treatment groups all favored continuous treatment: Diarrhea, $0.09(P=0.160)$; Indigestion, 0.25 $(P=0.002)$; Constipation, 0.14 $(P=0.050)$; Abdominal pain, $0.25(P=0.001)$; and Reflux, $0.54(P<0.001)$ (Fig. 3a). The estimated difference between the treatment groups in the Reflux dimension was of a magnitude considered to be clinically relevant. Mean QOLRAD scores at baseline and at the end of the short-term and maintenance treatment phases are shown in Fig. 3b. The estimated differences in the change from baseline to the end of maintenance treatment between the continuous and on-demand treatment groups were: Emotional, -0.28 $(P<0.001)$; Sleep disturbance, $-0.28 \quad(P<0.001)$; Food/ drink problems, $-0.38(P<0.001)$; Physical/social functioning, $-0.18(P=0.001)$; and Vitality, $-0.31(P<0.001)$; all differences favored continuous treatment (Fig. 3b).

\section{Safety}

Overall, the AE profile was similar between the two treatment groups, and the majority of AEs were mild or moderate in intensity. AEs were reported by $16.7 \%$ of patients during the short-term treatment phase, and 36.2 and $35.4 \%$ of patients during the on-demand and continuous maintenance phases, respectively. The most commonly reported AEs in the maintenance treatment phase were GI in nature (Table 5). There were no deaths during the study. In the maintenance phase, 1 patient in the on-demand treatment group and 7 patients in the continuous treatment group discontinued study treatment due to an $\mathrm{AE}(P=0.07)$.

SAEs were recorded for 4 patients in the on-demand treatment group and 11 patients in the continuous treatment group. With the exception of fracture, which occurred in 2 patients (1 humerus and 1 fibula), all SAEs occurred in 1 patient each (continuous treatment group: chest pain with dyspnea, renal pain, pulmonary embolism, aggravated angina pectoris, respiratory infection and hepatocellular damage, anemia, hernia [intervertebral disc], gastroenteritis and sinusitis; on-demand treatment group: meningitis, colon carcinoma, gastroenteritis and accidental injury with chest pain). However, none of 


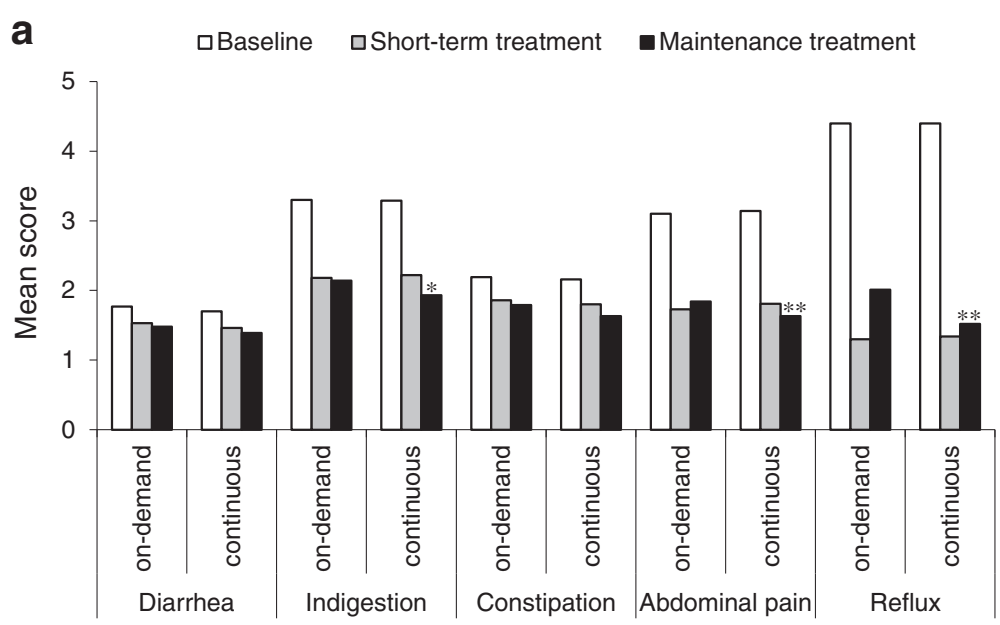

b aBaseline aShort-term treatment $\mathbf{a}$ Maintenance treatment

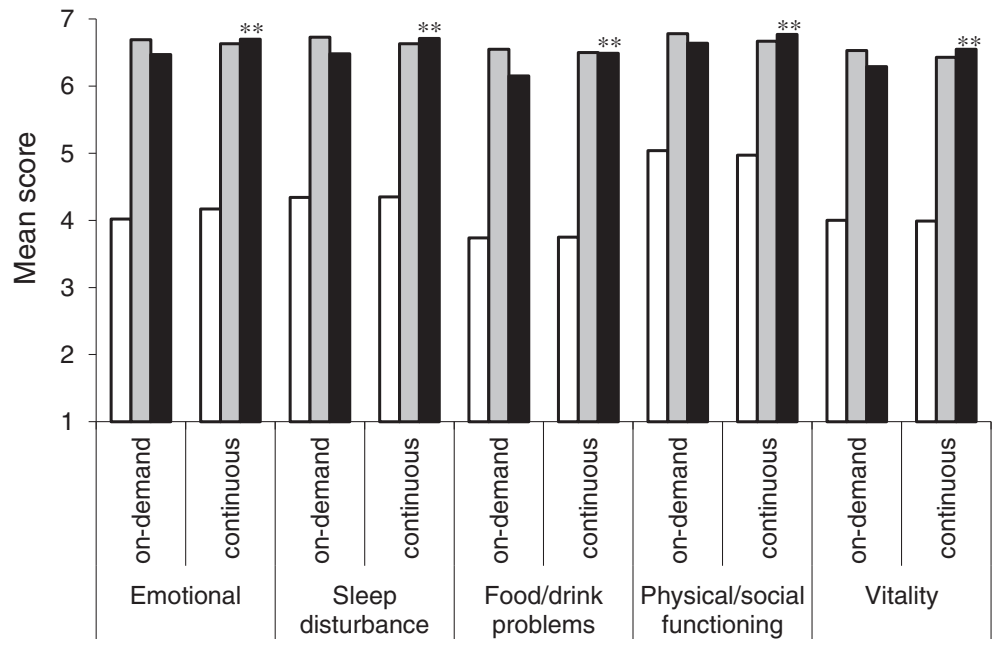

Fig. 3 Mean (a) Gastrointestinal Symptom Rating Scale and (b) Quality of Life in Reflux and Dyspepsia questionnaire scores at baseline ${ }^{a}$, following 4 weeks' initial (short-term) treatment with esomeprazole $20 \mathrm{mg}$ once daily, and after maintenance treatment with either on-demand or continuous

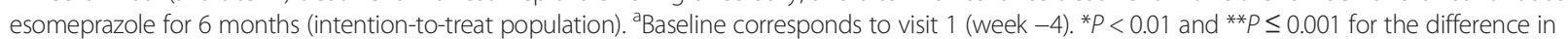
the change in scores from baseline to the end of maintenance treatment for continuous versus on-demand treatment groups

the SAEs were considered by study investigators to be causally related to the study treatment. There were no laboratory findings that raised any safety concerns.

\section{Discussion}

The results for the primary variable of this multinational study show that, following an initial 4-week symptom control phase with esomeprazole $20 \mathrm{mg}$ once daily, 6 months' on-demand maintenance treatment with esomeprazole $20 \mathrm{mg}$ was non-inferior to continuous treatment in terms of patients' willingness to continue treatment. The non-inferiority of on-demand versus continuous treatment was observed in both the ITT and PP populations, demonstrating that more serious protocol violations, such as the use of disallowed treatment to control reflux symptoms, did not appreciably alter the results for the primary variable. The results of the primary analysis were further supported by the finding that there was no statistically significant difference in the proportions of patients who were satisfied with the way of taking the drug, and with the effect of treatment. Indeed, although 18 and $14 \%$ of patients in the on-demand and continuous treatment groups, respectively, were either indifferent to or dissatisfied with the way their heartburn and regurgitation symptoms were being treated, only 3 patients $(1.0 \%)$ in the ondemand treatment group and 2 patients $(0.7 \%)$ in the continuous treatment group discontinued due to 
Table 5 Number of patients (\%) with the most commonly reported adverse events in the maintenance treatment phase ( $\geq 2 \%$ in any treatment group; safety population)

\begin{tabular}{lll}
\hline & \multicolumn{2}{l}{ Patients $[n(\%)]$} \\
\cline { 2 - 3 } & On-demand $(n=301)$ & Continuous $\left(n=294^{\mathrm{a}}\right)$ \\
\hline Flatulence & $15(5.0)$ & $12(4.1)$ \\
Abdominal pain & $10(3.3)$ & $9(3.1)$ \\
Diarrhea & $6(2.0)$ & $9(3.1)$ \\
Constipation & $9(3.0)$ & $5(1.7)$ \\
Viral infection & $12(4.0)$ & $8(2.7)$ \\
Headache & $5(1.7)$ & $7(2.4)$ \\
Respiratory infection & $7(2.3)$ & $6(2.0)$ \\
Gastroenteritis & $7(2.3)$ & $9(3.1)$ \\
Back pain & $5(1.7)$ & $7(2.4)$ \\
Arthralgia & $2(0.7)$ & $6(2.0)$ \\
\hline
\end{tabular}

${ }^{a}$ Three patients did not take any study drug and were therefore excluded from the safety population

unsatisfactory control of symptoms. This proportion is somewhat lower than was reported in an earlier 6month study $(n=342)$ examining the efficacy of esomeprazole on-demand treatment in patients with NERD; in this study, $14 \%$ of patients discontinued due to insufficient heartburn control (compared with $51 \%$ in the placebo group) [12].

It is well recognized that rates of remission from endoscopic relapse in patients with GERD are directly related to the degree of acid suppression achieved during therapy [21], and PPIs are the most effective treatment option in this regard. Among the PPIs, esomeprazole provides sustained acid suppression [11] that has translated into higher rates of maintenance of reflux esophagitis healing compared with lansoprazole [22] and pantoprazole [23]. Esomeprazole $20 \mathrm{mg}$ has also been approved in Europe for controlling symptoms in patients with NERD. Indeed, the efficacy of both esomeprazole $40 \mathrm{mg}$ and $20 \mathrm{mg}$ for the maintenance treatment of NERD has been demonstrated in placebo-controlled trials of continuous [24] and on-demand therapy [12, 20]. The on-demand use of PPIs, including esomeprazole, has also been compared with continuous use in several randomized clinical trials of patients with NERD or GERD [25-30]. Reviews have concluded that ondemand maintenance treatment with a PPI is an appropriate option for patients with mild reflux esophagitis and those with NERD [31-33], although some authors have questioned the efficacy of this approach for patients with healed reflux esophagitis [30]. Indeed, the results of an observational study suggest that an on-demand approach may more accurately match patient behavior, as some patients appear to use their treatment only as required for symptom control even when prescribed continuous therapy [34]. Despite extensive research in this area, to our knowledge, the present study is the first multinational study to investigate patient opinion of ondemand or continuous esomeprazole in patients with NERD who had responded to initial short-term treatment with a PPI.

Another potential advantage of on-demand treatment is that it is associated with lower medication use than continuous treatment. For example, a Japanese study examined the efficacy of maintenance treatment with omeprazole on-demand versus continuous in patients with NERD [35]. Over 24 weeks, mean study drug consumption ranged from 6.2 to 6.9 tablets per week in the continuous treatment group. In the on-demand treatment group, study drug consumption decreased over time, from 3.0 to 1.8 tablets per week [35]. In a further study, patients with NERD received esomeprazole ondemand or placebo for 6 months [12]. Mean intake of study medication was 0.34 , indicating a $66 \%$ reduction versus continuous once-daily intake [12]. In line with these findings, the present study showed that the use of study medication was reduced by $55 \%$ with on-demand versus continuous treatment, yet the willingness of patients to continue therapy was similar to that achieved with continuous treatment (and with comparable HRQoL). Mean intake of study medication in the ondemand treatment group was higher than previously reported [12], although this may have been a result of patients taking their medication for prevention as well as relief of symptoms.

The reduction in PPI use with on-demand versus continuous treatment has important economic implications, as it is likely to correspond to a reduction in the cost associated with maintenance treatment [12]. Indeed, in one study that assessed 6-months' maintenance treatment with esomeprazole $20 \mathrm{mg}$ on-demand, esomeprazole $20 \mathrm{mg}$ once daily or ranitidine $150 \mathrm{mg}$ twice daily, direct medical costs in patients with GERD were $€ 171.9$, $€ 221.6$ and $€ 248.8$, respectively. The total costs associated with maintenance treatment were also lowest for on-demand esomeprazole ( $€ 221.5, € 286.5$ and $€ 295.8$, respectively) [32, 36]. Similarly, in another study, 6months' on-demand treatment with esomeprazole $20 \mathrm{mg}$ incurred considerably lower direct medical costs than continuous treatment with omeprazole $20 \mathrm{mg}$ once daily in GERD patients without esophagitis [37].

There is a known risk of relapse of reflux esophagitis during maintenance treatment, including on-demand therapy [31]. Not surprisingly, therefore, a small number of patients $(n=15)$, all of whom had been treated with esomeprazole $20 \mathrm{mg}$ on-demand, had relapse with mucosal breaks at endoscopy after 6 months (the only objective observation in the present study), all of which were considered to be mild reflux esophagitis (14 with grade $\mathrm{A}$ and 1 with grade $\mathrm{B}$, according to the LA 
classification). However, previous studies have found that patients may change between a non-erosive stage and reflux esophagitis [38, 39]. It is possible, therefore, that a small proportion of these 15 patients had mild reflux esophagitis that, at visit 1, was in remission, mediated by the limited use of PPI therapy that was permitted before inclusion in the study. Until recently, monitoring the course of NERD was very difficult; only with the advent of histological examination of biopsies from the Z-line has it been possible to monitor progression, regression and normalization during therapy [40-42]. Indeed, a previous study in patients with NERD reported that 3 and 6 months of therapy with omeprazole $40 \mathrm{mg}$ led to complete recovery of dilation of intercellular spaces in more than $90 \%$ of patients, and that in all cases this was associated with regression of heartburn [40]. Technological advances have also meant that NERD can now be diagnosed based on the absence of esophageal lesions on endoscopy, with the results of one study reporting that modern video gastroscopy was able to recognize $76.4 \%$ of patients with NERD [43]. Combining histology and endoscopy could, therefore, improve the diagnosis and monitoring of disease progression during PPI treatment in patients with NERD.

Relative to on-demand treatment, continuous treatment was perhaps predictably associated with statistically significant improvements in single parameters of the GSRS and QOLRAD questionnaires. However, with the exception of the GSRS Reflux dimension, the differences in the change in GSRS and QOLRAD scores between the on-demand and continuous treatment groups were not deemed to be clinically relevant [44]. Moreover, patients in the on-demand treatment group took less medication than those randomized to continuous treatment, and the number of patients willing to continue treatment at 6 months was comparable between the two groups. Interestingly, despite the fact that $92 \%$ of patients were assessed by the investigator as being 'heartburn-free' at the end of the 4-week short-term treatment period, patient-reported scores in the GSRS Reflux dimension were approximately 1.3 in both the on-demand and continuous treatment groups. This suggests some degree of disagreement between investigator and patient assessments. The difference, however, can probably be explained by the nature of the GSRS questionnaire; the GSRS Reflux dimension encompasses both heartburn and acid regurgitation, whereas in our study, investigator assessments (and subsequent inclusion in the maintenance phase) related exclusively to heartburn.

In this study, on-demand treatment could be taken to prevent symptoms, to soothe symptoms, or both. For example, patients may have chosen to take their medication to prevent symptoms in stressful situations, or before the occurrence of known reflux triggers.
Although patients were asked whether they had taken medication to soothe or prevent symptoms, the exact reasons for usage of on-demand esomeprazole were not recorded. To further develop our understanding of patient behavior, more research into the reasons for taking on-demand medication is required.

The implications of H. pylori infection on management of GERD remains controversial [45]. For example, studies have shown that $H$. pylori-infected patients with GERD tend to have higher response rates to acidsuppressive treatment than $H$. pylori-negative patients. More than $40 \%$ of patients in the present study were $H$. pylori-positive. This may have implications for the effectiveness of on-demand treatment, because H. pylori may be synergistic in preventing or treating reflux esophagitis when less than optimal acid suppression is used $[46,47]$. Nonetheless, the primary variable was unaffected by $H$. pylori status in the present study.

Limitations of this study include its open-label nature and the fact that patients underwent endoscopy at study end and upon discontinuation, but not at regular intervals during the study. In addition, the study only included NERD patients who had complete resolution of heartburn symptoms following initial treatment with esomeprazole; therefore, it is possible that results may have been less favorable in patients whose response to short-term treatment was not complete. Strengths of the study, on the other hand, include the multinational nature of the study population, the use of validated instruments to assess symptoms (GSRS) and quality of life (QOLRAD), and the use of three different measures of patient opinion about the impact of on-demand or continuous treatment (discontinuation due to unsatisfactory treatment, standardized treatment satisfaction questionnaire and the quality of life questionnaire).

\section{Conclusions}

Using the measure 'willingness to continue treatment', 6 months of on-demand esomeprazole maintenance treatment was non-inferior to continuous maintenance treatment in patients with NERD who had achieved complete symptom resolution following 4 weeks of treatment with esomeprazole. Although continuous treatment gave significantly better symptom control than on-demand treatment, as measured by the GSRS questionnaire, only the difference in the Reflux dimension reached a magnitude that was clinically relevant. As may have been expected, medication intake was lower with on-demand treatment, with obvious potential benefits in terms of cost of treatment and convenience to patients.

\section{Abbreviations}

AE: adverse event; Cl: confidence interval; GERD: gastroesophageal reflux disease; GI: gastrointestinal; GSRS: Gastrointestinal Symptom Rating Scale; HRQOL: health-related quality of life; ITT: intention to treat; NERD: non-erosive 
reflux disease; PP: per protocol; PPI: proton pump inhibitor; QOLRAD: Quality of Life in Reflux and Dyspepsia; SD: standard deviation.

\section{Competing interests}

Ekkehard Bayerdörffer has received financial support from AstraZeneca for scientific lectures.

Marc-Andre Bigard has received financial support for scientific lectures from AstraZenenca, Reckitt Benckiser, Bayer HealthCare, Merck and Abbvie. Juan Enrique Dominguez Muñoz, Hennie Grundling, Fermín Mearin, Luis Rodrigo and Werner Weiss have no conflicts of interest to declare. Tore Persson, Lars-Erik Svedberg, Nanna Keeling and Stefan Eklund are current (or former) employees of AstraZeneca.

\section{Authors' contributions}

EB was the international coordinating investigator for the study, and had major input into the study design, conduct and analysis. M-AB, WW, FM, LR, JEDM and HG were principal investigators; they commented on and approved the study design and recruited patients to the study. TP performed the statistical analysis. L-ES provided input into the study design and was responsible for patient safety and the safety analysis. NK provided input into the study design and coordinated the study. SE had major input into the study design, conduct and analysis. All authors were involved in drafting or revising the manuscript, and read and approved the final manuscript. CONSORT guidelines were followed during the development of this manuscript.

\section{Acknowledgments}

We thank Claire Byrne, Katharine Williams and Steve Winter, from inScience Communications, Springer Healthcare who provided medical writing support funded by AstraZeneca.

This study was funded by AstraZeneca R\&D, Gothenburg, Sweden (study code: SH-NEG-0004; protocol available from http://www.astrazenecaclinicaltrials.com/). We are indebted to the following investigators for their participation in this study. In Austria: K. Schütze (Vienna), W. Rainer (Knittelfeld), G. Gombotz (Feldbach), R. Herrmann (Zell am See), H. Fabian (Leoben), W. Franz (Kittsee), and H. Kiss (Oberwart). In Finland: P. Sipponen (Espoo). In France: S. lochum (Vandoeuvre Les Nancy), J.-P. Blime (Epinal), C. Lauvaux (Saint Die), J. Grandquillaume (Belfort), J.-Y. Canva (Douai), M. Lapprand (Lille), R. Kornhauser (Arras), J.-P. Aubet (Rouen), M. Colson (Istres), P. Courtial (Nimes), J. Boulant (Grasse), P. A. Bounin (Cagnes Sur Mer), A. Le Texier (Cannes La Bocca), F. Hedelius (Saint Priest), J.-P. Lemaitre (Clermont Ferrand), G. Coulanjon (Issoire), P. Geoffroy (Epernay), M. Gompel (Montelimar), J.-L. Guisset (Narbonne), E. Mathoniere (Vitry Sur Seine), G. Tordjman (Creteil), F. Venezia (Charenton Le Pont), E. Zrihen (Vitry Sur Seine), J.-F. Peignot (Paris), H. Roche (Velizy Villacoublay), C. Barberis (Talence), D. Goldfain (Dreux), S. Sultan (Saint Denis), M. Lhermie (Douai), W. Berrebi (Paris), G. Leothaud (Ales), A. Tarasco (Beziers), and O. Delette (Lille). In Germany: M. Schumacher (Wolmirstedt), K. Heinrich (Kronach), J. Habbig (Köln), K. Ziegler (Berlin), E. Massmann (Münster), P.-P. Pech (Münster), M. Buchner (Ribnitz), R.-R. Fink (Freising), H. Böneke (Lienen), E. Bästlein (Köln), W. Brandt (Potsdam), H. Jürgens (Oelde), C. Haferland (Görlitz), and D. Klein (Cologne). In South Africa: H. Grundling (Bloemfontein), J. Louw (Cape Town), T. A. Winter (Cape Town), A. Simjee (Durban), N. Aboo (Durban), C. van Rensberg (Stellenbosch), S. Schmidt (Bellville), P. van Eeden (Bellville), S. van der Merwe (Centurion), C. Kassianides (Johannesburg), H. Schneider (Johannesburg), and R. Ally (Johannesburg). In Spain: F. Carballo Álvarez (Guadalajara), J. Manuel Herrerías Gutierrez (Sevilla), and C. Losa Martínez (Madrid).

We would also like to thank Emma Nauclér for statistical input during the preliminary drafts of the manuscript.

\section{Author details}

${ }^{1}$ Department of Internal Medicine, Lohr Health Centre, Lohr, Germany. ${ }^{2}$ Gastroenterology Unit, University Hospital, Vandoeuvre les Nancy, France. ${ }^{3} 4$ th Medical Department, Hospital Rudolfstiftung, Vienna, Austria. ${ }^{4}$ Gastroenterology Service, Centro Médico Teknon, Barcelona, Spain. ${ }^{5}$ Gastroenterology Service, Hospital Central de Asturias, Oviedo, Spain. ${ }^{6}$ Department of Gastroenterology, University Hospital, Santiago de Compostela, Spain. ${ }^{7}$ Department of Internal Medicine, Universitas Hospital, Bloemfontein, South Africa. ${ }^{8}$ AstraZeneca R\&D, Gothenburg, Sweden.

Received: 9 February 2016 Accepted: 25 February 2016 Published online: 14 April 2016

\section{References}

1. Kaynard A, Flora K. Gastroesophageal reflux disease. Control of symptoms, prevention of complications. Postgrad Med. 2001;110(3):42-4. 4 7-8, 51-3.

2. Vakil N, van Zanten SV, Kahrilas P, Dent J, Jones R. The Montreal definition and classification of gastroesophageal reflux disease: a global evidencebased consensus. Am J Gastroenterol. 2006;101(8):1900-20. quiz 43.

3. Locke 3rd GR, Talley NJ, Fett SL, Zinsmeister AR, Melton 3rd LJ. Prevalence and clinical spectrum of gastroesophageal reflux: a population-based study in Olmsted County, Minnesota. Gastroenterology. 1997;112(5):1448-56.

4. Hershcovici T, Fass R. Nonerosive Reflux Disease (NERD) - an update. J Neurogastroenterol Motil. 2010;16(1):8-21.

5. Havelund T, Lind T, Wiklund I, Glise H, Hernqvist H, Lauritsen K, et al. Quality of life in patients with heartburn but without esophagitis: effects of treatment with omeprazole. Am J Gastroenterol. 1999;94(7):1782-9.

6. Kulig M, Leodolter A, Vieth M, Schulte E, Jaspersen D, Labenz J, et al. Quality of life in relation to symptoms in patients with gastro-oesophageal reflux disease- an analysis based on the ProGERD initiative. Aliment Pharmacol Ther. 2003;18(8):767-76.

7. Bell NJ, Burget D, Howden CW, Wilkinson J, Hunt RH. Appropriate acid suppression for the management of gastro-oesophageal reflux disease. Digestion. 1992;51 Suppl 1:59-67.

8. Lind T, Havelund T, Carlsson R, Anker-Hansen O, Glise H, Hernqvist H, et al. Heartburn without oesophagitis: efficacy of omeprazole therapy and features determining therapeutic response. Scand J Gastroenterol. 1997;32(10):974-9.

9. Freston JW, Malagelada JR, Petersen H, McCloy RF. Critical issues in the management of gastroesophageal reflux disease. Eur J Gastroenterol Hepatol. 1995;7(6):577-86.

10. Miner Jr P, Katz PO, Chen Y, Sostek M. Gastric acid control with esomeprazole, lansoprazole, omeprazole, pantoprazole, and rabeprazole: a five-way crossover study. Am J Gastroenterol. 2003;98(12):2616-20.

11. Röhss K, Wilder-Smith C, Nauclér E, Jansson L. Esomeprazole 20 mg provides more effective intragastric acid control than maintenance-dose rabeprazole, lansoprazole or pantoprazole in healthy volunteers. Clin Drug Investig. 2004;24(1):1-7.

12. Talley NJ, Lauritsen K, Tunturi-Hihnala H, Lind T, Moum B, Bang C, et al. Esomeprazole $20 \mathrm{mg}$ maintains symptom control in endoscopy-negative gastro-oesophageal reflux disease: a controlled trial of 'on-demand' therapy for 6 months. Aliment Pharmacol Ther. 2001;15(3):347-54.

13. Armstrong D, Bennett JR, Blum AL, Dent J, De Dombal FT, Galmiche JP, et al. The endoscopic assessment of esophagitis: a progress report on observer agreement. Gastroenterology. 1996;111(1):85-92.

14. Dixon MF, Genta RM, Yardley JH, Correa P. Classification and grading of gastritis. The updated Sydney System. International Workshop on the Histopathology of Gastritis, Houston 1994. Am J Surg Pathol. 1996;20(10):1161-81.

15. Revicki DA, Wood M, Wiklund I, Crawley J. Reliability and validity of the Gastrointestinal Symptom Rating Scale in patients with gastroesophageal reflux disease. Qual Life Res. 1998;7(1):75-83.

16. Kulich KR, Wiklund I, Junghard O. Factor structure of the Quality of life in reflux and dyspepsia (QOLRAD) questionnaire evaluated in patients with heartburn predominant reflux disease. Qual Life Res. 2003;12(6):699-708.

17. Wiklund IK, Junghard O, Grace E, Talley NJ, Kamm M, Veldhuyzen van Zanten S, et al. Quality of life in reflux and dyspepsia patients. Psychometric documentation of a new disease-specific questionnaire (QOLRAD). Eur J Surg Suppl. 1998;164(583):41-9.

18. Drummond HE, Ghosh S, Ferguson A, Brackenridge D, Tiplady B. Electronic quality of life questionnaires: a comparison of pen-based electronic questionnaires with conventional paper in a gastrointestinal study. Qual Life Res. 1995;4(1):21-6.

19. Lundell LR, Dent J, Bennett JR, Blum AL, Armstrong D, Galmiche JP, et al. Endoscopic assessment of oesophagitis: clinical and functional correlates and further validation of the Los Angeles classification. Gut. 1999;45(2):172-80.

20. Talley NJ, Venables TL, Green JR, Armstrong D, O'Kane KP, Giaffer M, et al. Esomeprazole $40 \mathrm{mg}$ and $20 \mathrm{mg}$ is efficacious in the long-term management of patients with endoscopy-negative gastro-oesophageal reflux disease: a placebo-controlled trial of on-demand therapy for 6 months. Eur J Gastroenterol Hepatol. 2002;14(8):857-63.

21. Johnson DA, Katz PO, Levine D, Röhss K, Astrand M, Junghard O, et al. Prevention of relapse of healed reflux esophagitis is related to the duration of intragastric pH > 4. J Clin Gastroenterol. 2010;44(7):475-8. 
22. Lauritsen K, Devière J, Bigard MA, Bayerdörffer E, Mózsik G, Murray F, et al. Esomeprazole $20 \mathrm{mg}$ and lansoprazole $15 \mathrm{mg}$ in maintaining healed reflux oesophagitis: Metropole study results. Aliment Pharmacol Ther. 2003;17(3):333-41.

23. Labenz J, Armstrong D, Lauritsen K, Katelaris P, Schmidt S, Schütze K, et al. Esomeprazole $20 \mathrm{mg}$ vs. pantoprazole $20 \mathrm{mg}$ for maintenance therapy of healed erosive oesophagitis: results from the EXPO study. Aliment Pharmacol Ther. 2005:22(9):803-11.

24. Katz PO, Castell DO, Levine D. Esomeprazole resolves chronic heartburn in patients without erosive oesophagitis. Aliment Pharmacol Ther. 2003;18(9):875-82.

25. Tsai HH, Chapman R, Shepherd A, McKeith D, Anderson M, Vearer D, et al. Esomeprazole $20 \mathrm{mg}$ on-demand is more acceptable to patients than continuous lansoprazole $15 \mathrm{mg}$ in the long-term maintenance of endoscopy-negative gastro-oesophageal reflux patients: the COMMAND study. Aliment Pharmacol Ther. 2004;20(6):657-65.

26. Pace F, Negrini C, Wiklund I, Rossi C, Savarino V. Quality of life in acute and maintenance treatment of non-erosive and mild erosive gastro-oesophageal reflux disease. Aliment Pharmacol Ther. 2005;22(4):349-56.

27. Janssen W, Meier E, Gatz G, Pfaffenberger B. Effects of pantoprazole 20 mg in mild gastroesophageal reflux disease: once-daily treatment in the acute phase, and comparison of on-demand versus continuous treatment in the long term. Curr Ther Res Clin Exp. 2005;66(4):345-63.

28. Norman Hansen A, Bergheim R, Fagertun H, Lund H, Moum B. A randomised prospective study comparing the effectiveness of esomeprazole treatment strategies in clinical practice for 6 months in the management of patients with symptoms of gastroesophageal reflux disease. Int J Clin Pract. 2005;59(6):665-71.

29. Bour B, Staub JL, Chousterman M, Labayle D, Nalet B, Nouel O, et al. Long-term treatment of gastro-oesophageal reflux disease patients with frequent symptomatic relapses using rabeprazole: on-demand treatment compared with continuous treatment. Aliment Pharmacol Ther. 2005;21(7):805-12.

30. Sjöstedt S, Befrits R, Sylvan A, Harthon C, Jörgensen L, Carling L, et al. Daily treatment with esomeprazole is superior to that taken on-demand for maintenance of healed erosive oesophagitis. Aliment Pharmacol Ther. 2005;22(3):183-91.

31. Bardhan KD. Intermittent and on-demand use of proton pump inhibitors in the management of symptomatic gastroesophageal reflux disease. Am J Gastroenterol. 2003;98 Suppl 3:S40-8.

32. Pace F, Porro GB. On-demand PPI therapy in GERD. Curr Treat Options Gastroenterol. 2008;11(1):35-42.

33. Pace F, Tonini M, Pallotta S, Molteni P, Porro GB. Systematic review: maintenance treatment of gastro-oesophageal reflux disease with proton pump inhibitors taken 'on-demand'. Aliment Pharmacol Ther. 2007;26(2):195-204.

34. Hungin AP, Rubin GP, O'Flanagan $\mathrm{H}$. Long-term prescribing of proton pump inhibitors in general practice. Br J Gen Pract. 1999;49(443):451-3.

35. Nagahara A, Hojo M, Asaoka D, Sasaki H, Watanabe S. A randomized prospective study comparing the efficacy of on-demand therapy versus continuous therapy for 6 months for long-term maintenance with omeprazole $20 \mathrm{mg}$ in patients with gastroesophageal reflux disease in Japan. Scand J Gastroenterol. 2014:49(4):409-17.

36. Hansen $A N$, Wahlqvist $P$, Jørgensen $E$, Bergheim $R$, Fagertun $H$, Lund $H$, et al. Six-month management of patients following treatment for gastroesophageal reflux disease symptoms - a Norwegian randomized, prospective study comparing the costs and effectiveness of esomeprazole and ranitidine treatment strategies in a general medical practitioners setting. Int J Clin Pract. 2005;59(6):655-64.

37. Wahlqvist $P$, Junghard $O$, Higgins A, Green J. Cost effectiveness of proton pump inhibitors in gastro-oesophageal reflux disease without oesophagitis: comparison of on-demand esomeprazole with conventional omeprazole strategies. Pharmacoeconomics. 2002;20(4):267-77.

38. Labenz J, Malfertheiner P. Treatment of uncomplicated reflux disease. World J Gastroenterol. 2005;11(28):4291-9.

39. Labenz J, Nocon M, Lind T, Leodolter A, Jaspersen D, Meyer-Sabellek W, et al. Prospective follow-up data from the ProGERD study suggest that GERD is not a categorial disease. Am J Gastroenterol. 2006;101(11):2457-62.

40. Calabrese C, Bortolotti M, Fabbri A, Areni A, Cenacchi G, Scialpi C, et al. Reversibility of GERD ultrastructural alterations and relief of symptoms after omeprazole treatment. Am J Gastroenterol. 2005;100(3):537-42.
41. Vieth M, Haringsma J, Delarive J, Wiesel PH, Tam W, Dent J, et al. Red streaks in the oesophagus in patients with reflux disease: is there a histomorphological correlate? Scand J Gastroenterol. 2001;36(11):1123-7.

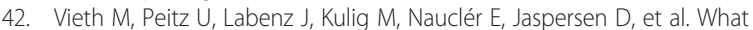
parameters are relevant for the histological diagnosis of gastroesophageal reflux disease without Barrett's mucosa? Dig Dis. 2004;22(2):196-201.

43. Antos D, Bayerdörffer $E$, Bästlein E. New evaluation of endoscopic criteria in NERD patients. Gastroenterology. 2005;128 Suppl 2:A382.

44. Juniper EF, Guyatt GH, Willan A, Griffith LE. Determining a minimal important change in a disease-specific quality of life questionnaire. J Clin Epidemiol. 1994;47(1):81-7.

45. Katelaris PH. Gastro-oesophageal reflux disease and Helicobacter pylori. Minerva Gastroenterol Dietol. 2003;49(4):235-41.

46. Dent J. Review article: is Helicobacter pylori relevant in the management of reflux disease? Aliment Pharmacol Ther. 2001;15 Suppl 1:16-21.

47. Malfertheiner P, Peitz U. The interplay between Helicobacter pylori, gastrooesophageal reflux disease, and intestinal metaplasia. Gut. 2005;54 Suppl 1: i13-20.

\section{Submit your next manuscript to BioMed Central and we will help you at every step:}

- We accept pre-submission inquiries

- Our selector tool helps you to find the most relevant journal

- We provide round the clock customer support

- Convenient online submission

- Thorough peer review

- Inclusion in PubMed and all major indexing services

- Maximum visibility for your research

Submit your manuscript at www.biomedcentral.com/submit
C Biomed Central 